\title{
THE EFFECT OF METRONIDAZOLE ON THE VIABILITY OF CAL-27 TONGUE CANCER CELLS
}

\author{
NATALIA TOŁOCZKO-IWANIUK ${ }^{1,2 *}$, DOROTA DZIEMIAŃCZYK-PAKIEŁA ${ }^{2}$, \\ KATARZYNA CELIŃSKA-JANOWICZ ${ }^{1}$, PAWEŁ DRĄGOWSKI ${ }^{1}$, DAWID GROTH ${ }^{3}$, \\ JOANNA RESZEĆ ${ }^{4}$, HALINA CAR ${ }^{5}$, JAN BORYS ${ }^{2}$ and WOJCIECH MILTYK ${ }^{1}$
}

${ }^{1}$ Department of Pharmaceutical Analysis, Medical University of Białystok, Mickiewicza 2D, 15-522 Białystok, Poland

${ }^{2}$ Department of Maxillofacial and Plastic Surgery, Medical University of Białystok, Skłodowskiej-Curie 24A, 15-276 Białystok, Poland

${ }^{3}$ Department of Regenerative Medicine and Immune Regulation,

Medical University of Białystok, Waszyngtona 13, 15-269 Białystok, Poland

${ }^{4}$ Department of Medical Pathomorphology, Medical University of Białystok,

Waszyngtona 13, 15-269 Białystok, Polandm

${ }^{5}$ Department of Experimental Pharmacology, Medical University of Białystok, Szpitalna 37, 15-295 Białystok, Poland

\begin{abstract}
Metronidazole belongs to the most commonly prescribed medications for bacterial and parasitic infections worldwide. It is also used in perioperative prevention prior to bowel, and head and neck surgeries. Despite the fact that the World Health Organization has placed it on its List of Essential Medicines, it is considered potentially carcinogenic. A great number of research studies have been conducted to clarify this issue, but the results are inconclusive. None of the studies focused on the influence of metronidazole on oral cancer development. The aim of our study was to evaluate the impact of metronidazole on the viability of tongue cancer cells. The research was conducted on the tongue squamous cell carcinoma cell line (CAL-27). Metronidazole dissolved in growth medium was applied to the cell culture at concentrations: $1,10,50,100 \mu \mathrm{g} / \mathrm{mL}$. Toxicity of the drug was evaluated by MTT assay and the $\left[{ }^{3} \mathrm{H}\right]$-thymidine incorporation test. The MTT test revealed a significant increase in cell viability under the influence of metronidazole after $24 \mathrm{~h}$, at the highest concentration of the drug $(100 \mu \mathrm{g} / \mathrm{mL})$, but had no impact on cell viability at other concentrations and after $48 \mathrm{~h}$ and $72 \mathrm{~h}$. The results of the $\left[{ }^{3} \mathrm{H}\right]$-thymidine incorporation test did not show significant results. Summarizing, metronidazole stimulates the viability of tongue squamous cell carcinoma cells according to its concentration and the time of incubation (results significant at the concentration $100 \mu \mathrm{g} / \mathrm{mL}$, after $24 \mathrm{~h}$ of incubation).
\end{abstract}

Keywords: CAL-27, carcinogenic potential of drugs, metronidazole, oral cancer

Abbreviations: FBS - fetal bovine serum, 5-FU - 5-fluorouracil, PBS - phosphate-buffered saline, HM - 1-(2hydroxyethyl)-2-hydroxymethyl-5-nitroimidazole, AAM - 1-acetic acid-2-methyl-5-nitroimidazole, FADU fluorescence analysis of DNA unwinding method, IARC -International Agency for Research on Cancer, MTR - metronidazole

Metronidazole (2-(2-methyl-5-nitro-1H-imidazol-1-yl)ethanol) is one of the most commonly prescribed antibacterial and antiprotozoal medications worldwide. For over 50 years it has been widely utilised in the treatment of numerous diseases such as anaerobic bacterial infections (Bacteroides, Fusobacterium, Clostridium, Peptostreptococcus or Prevotella species), trichomoniasis, bacterial vagi- nosis, enteritis infectious, Crohn's disease, endocarditis, aspiration pneumonia, periodontitis, amoebic dysentery, Helicobacter pylori or Giardia lamblia infections. It has been included in perioperative prevention protocols for bowel or head and neck surgeries as well $(1,2,3)$. Moreover, it has been used is cancer treatment, with both radiotherapy and chemotherapy, making both treatment modalities

\footnotetext{
* Corresponding author: e-mail: n.toloczko@gmail.com
} 
more effective. It has been used as a radiosensitizer for hypoxic cells, e.g. in head and neck cancer radiotherapy or in combination with 5-fluorouracil (5FU) in the chemotherapeutic treatment of metastatic colorectal cancer. Less frequently, metronidazole has been used as a single medication for colon cancer $(4,5)$. The World Health Organisation has placed it on its List of Essential Medicines, a list of the most important medication needed in a basic health system $(6,7)$.

Metronidazole can affect mainly anaerobic organisms. It inhibits nucleic acid synthesis by disrupting the DNA of microbial cells. This situation occurs only if metronidazole is partially reduced, and since e this reduction usually happens in anaerobic cells, it is considered to have relatively little influence on aerobic cells, including humans cells (1). There is a great number of articles in the available literature discussing the problem of the carcinogenic potential of metronidazole. Despite the fact that much research has been conducted, the results are still not inconclusive. Furthermore, there is a lack of reports regarding the influence of this drug on oral cancer development.

Oral cancer is still a considerable problem as each year 450,000 new cases are diagnosed worldwide and two-thirds of them occur in developing countries. It belongs to a group of cancers commonly referred to as head and neck cancers - it comprises approximately $85 \%$ of that category. Head and neck cancer (localized in the upper aerodigestive tract) is the sixth leading cancer by

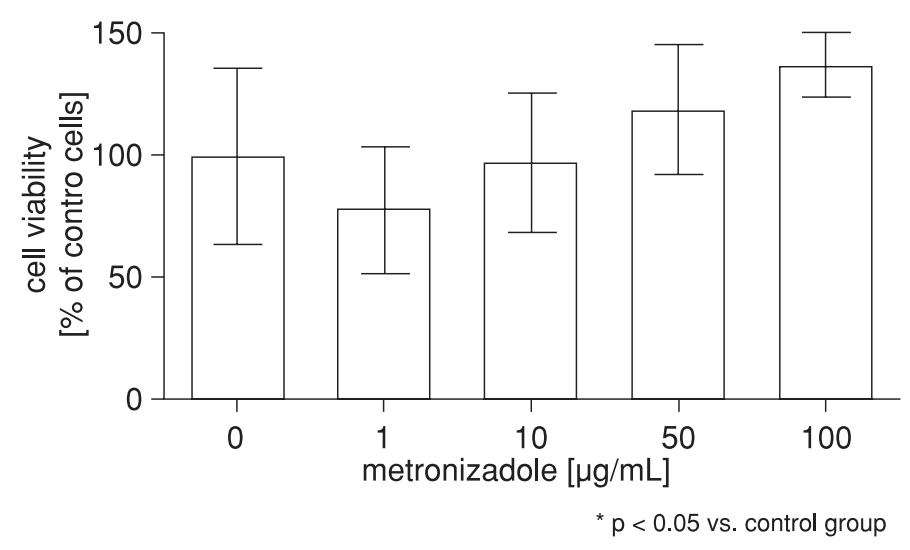

Figure 1 . Cells viability after $24 \mathrm{~h}$

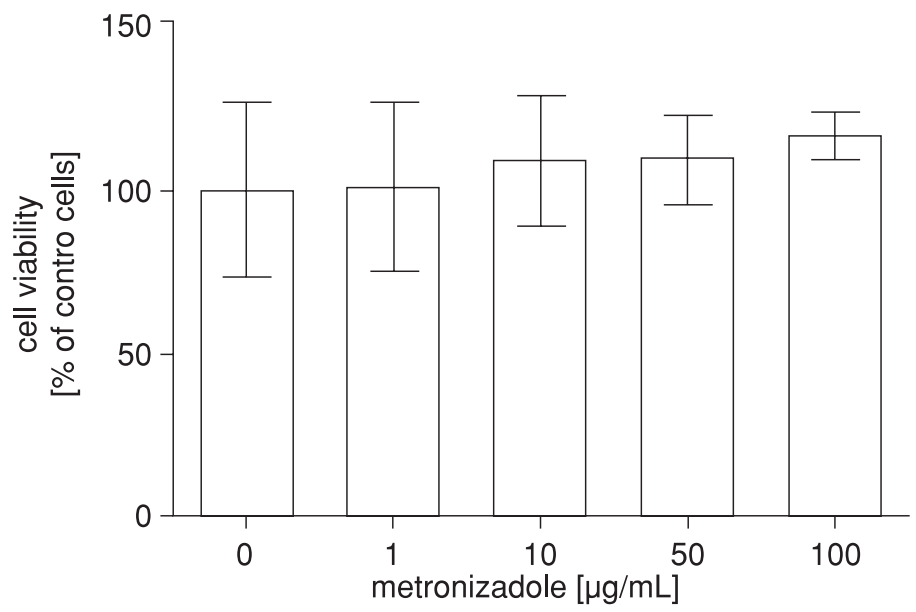

Figure 2. Cells viability after 48 h 


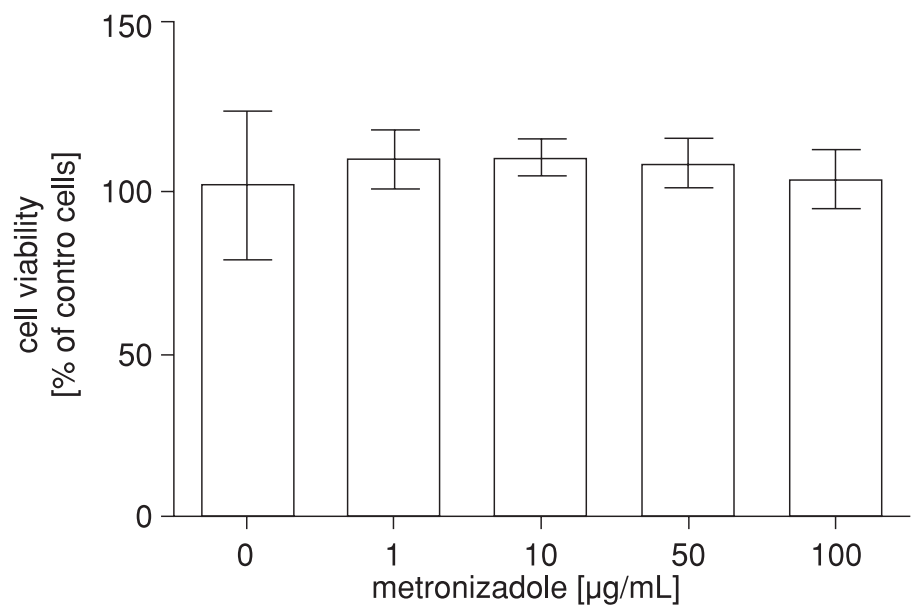

Figure 3. Cells viability after $72 \mathrm{~h}$

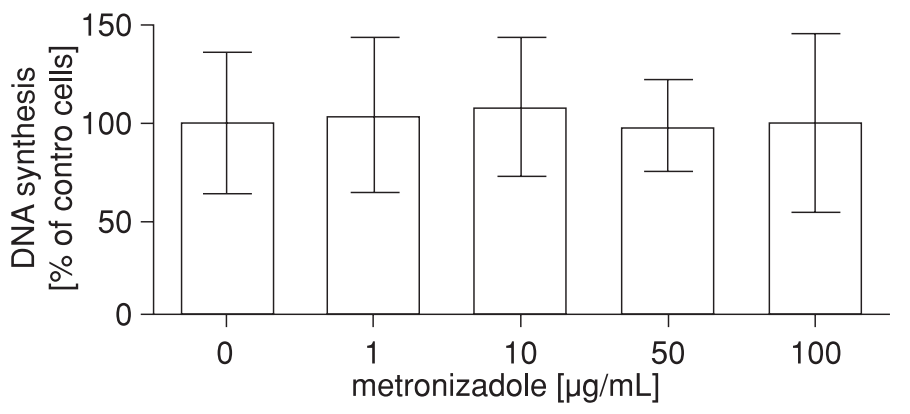

Figure 4. DNA biosynthesis after $24 \mathrm{~h}$

incidence worldwide and account for $6 \%$ of all cancer cases. Malignancies of the oral cavity may evolve in the unchanged mucosa, but more frequently they arise from premalignant oral lesions (leukoplakia, erythroplasia, lichen planus) $(8,9$, 10, 11).

Standards in the treatment of this disease are surgery and postoperative radiotherapy. The 5year survival rate ranges between $40 \%$ and $70 \%$, depending on the location, tumor stage or presence of metastases. The greatest problems regarding treatment, which also constitute the principal cause of therapy failure, are local recurrence of the tumor and occurrence of a second primary tumor. Second primary malignancies are not confined to the oral cavity; they occur in other locations exposed to similar carcinogenic factors, particu- larly various tissues of the aerodigestive tract (lung or esophageal cancer). They are detected among $10 \%$ to $40 \%$ of patients. Tumors located in the head and neck region affect a number of critical human functions including speech, communication, swallowing, eating, and appearance. Therefore, they cause considerable psychological distress and lead to the deterioration of a patient's quality of life $(8,9,10,11)$.

The aim of the current study was to evaluate the impact of metronidazole on the viability of tongue cancer cell lines.

\section{EXPERIMENTAL}

The research was conducted on tongue squamous cell carcinoma cell lines (CAL-27), purchased 
from the American Type Culture Collection (ATCC, Manassas, USA), since the tongue is one of the most common locations of this malignancy. The cells were kept in DMEM (Gibco, Thermo Fisher Scientific, Waltham, Massachusetts, USA), supplemented with $10 \%$ fetal bovine serum (FBS, Gibco), $50 \mathrm{U} / \mathrm{mL}$ penicillin (Gibco), $50 \mathrm{mg} / \mathrm{mL}$ streptomycin (Gibco), at $37^{\circ} \mathrm{C}$ in a $5 \% \mathrm{CO}_{2}$ incubator, in 10 $\mathrm{mL}$ plates (Sarstedt, USA).

Metronidazole purum (>98\%) was supplied by Sigma Chemical Co (St. Louis, Mo). The drug was dissolved in a growth medium and then added to the cell culture at concentrations: $1,10,50,100 \mu \mathrm{g} / \mathrm{mL}$. The toxicity of metronidazole was evaluated by MTT assay. Cells reached confluence on day 3 and were subsequently sifted to the 96 well plates (Sarstedt, USA) with $0.2 \mathrm{~mL}$ of growth medium, 20,000 cells per well. The respective drug concentrations were added to each well after $24 \mathrm{~h}$ of incubation. Following that, the cells were incubated for 24, 48 and $72 \mathrm{~h}$. After the incubation, the medium was removed and MTT (Thiazolyl Blue Tetrazolium Bromide - M5655, SIGMA-ALDRICH, St.Louis, USA) diluted in PBS (concentration $5 \mathrm{mg} / \mathrm{ml}$ ) was added. After $15 \mathrm{~min}$ of incubation at $37^{\circ} \mathrm{C}$, the cells were dissolved in $200 \mu \mathrm{L}$ of Isopropyl alcohol with $2 \mu \mathrm{L}$ of Sorensen's buffer. The results were then recorded with a spectrophotometer (Asys UVM 340, Biogenet) at $570 \mathrm{~nm}$ of wavelength.

The influence of metronidazole on cell proliferation was evaluated with the $\left[{ }^{3} \mathrm{H}\right]$-thymidine incorporation test. The cells were seeded in 24 well plates with $1 \mathrm{~mL}$ of medium, 50,000 cells per well. After $24 \mathrm{~h}$ of incubation, respective concentrations of metronidazole were added. The results were assessed after the following 24, 48 and $72 \mathrm{~h}$. Four hours before assessing the results $0.5 \mathrm{mCi}$ of $\left[{ }^{3} \mathrm{H}\right]$-thymidine (Hartman Analytic $\mathrm{GmbH}$, Braunschweig, Germany) was added to the medium. Incorporation of the marker into DNA was measured using a scintillation counter - Liquid Scintillation Analyzer TriCarb 2810 TR (Perkin Elmer) and calculated using Quanto Smart TM software (Perkin Elmer).

All data were extracted from original sources to fields within an Excel (Microsoft, Redmond, WA) database. The mean values of 3 independent experiments were used, each had 8 replicants. Data manipulation and analysis were conducted using

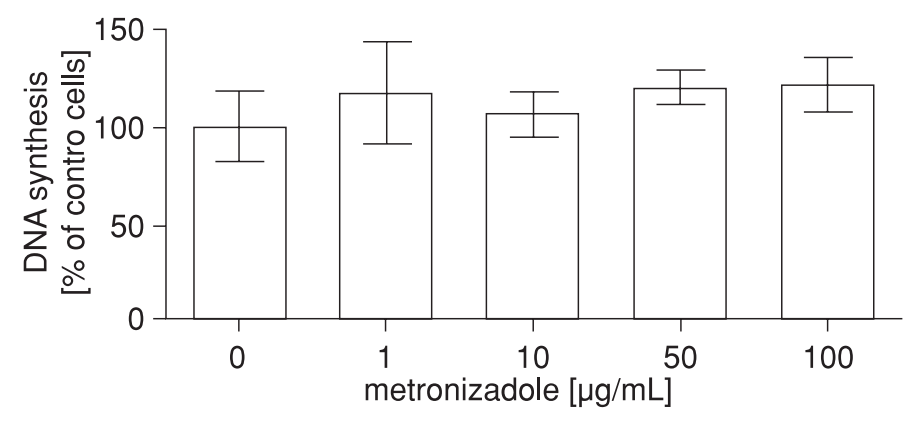

Figure 5. DNA biosynthesis after $48 \mathrm{~h}$

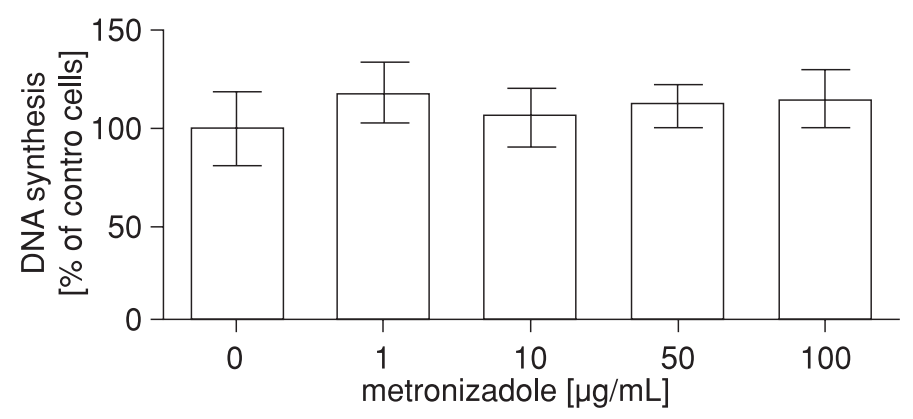

Figure 6. DNA biosynthesis after $72 \mathrm{~h}$ 
GraphPad Prism software for Mac OS X, version 7 (GraphPad Software, La Jolla California USA). To evaluate the statistical significance, comparison of five studied groups was performed using ANOVA (Dunnett's multiple comparison test). Values of $\mathrm{p}<$ 0.05 were considered statistically significant.

\section{RESULTS}

A statistically significant increase in cell viability under the influence of metronidazole was found at the highest concentration of the drug (100 $\mu \mathrm{g} / \mathrm{mL}$ ) after $24 \mathrm{~h}$ of incubation (Fig. 1). No significant impact on cell viability has been proved at other concentrations after 48 and 72 h (Figs. 2, 3).

The $\left[{ }^{3} \mathrm{H}\right]$-thymidine incorporation test results did not show any statistically significant differences in cell proliferation depending on applied metronidazole concentrations and the time of incubation (Figs. 4-6).

\section{DISCUSSION}

Metronidazole is widely used as an antibacterial and antiprotozoal medication, although it acts predominantly against anaerobes. It is used as an inactive prodrug. As a low molecular weight compound, it can diffuse into the cell through its membrane. Anaerobic organisms reduce the unionized drug intracellularly to its active form by the pyruvate: ferredoxin oxidoreductase system. The nitro groups of metronidazole capture electrons that would normally be transferred to hydrogen ions in this cycle. This promotes the formation of intermediate compounds and free radicals that are toxic to the cell which can link with DNA, change its helical structure and inhibit the synthesis of nucleic acids, which ultimately leads to bacterial cell death (12).

If only anaerobic cells have the ability to activate metronidazole, why is it believed that the drug affects also aerobic cells, including humans', and acts like a carcinogen? There are three main hypotheses offering explanation of this process:

- Nitroreduction hypothesis

In aerobic cells, the reduction of the nitro group of metronidazole is mediated by $\mathrm{NADH}$, xanthine oxidase, NADPH cytochrome P450 reductase, and NADPH cytochrome c reductase. An electrolytically reduced drug is responsible for extensive DNA damage by loss of helix conformation, strand breakage and, possibly, conversion of nitrogen bases. However, there are no published research results demonstrating the reduction of human plasma metabolites in this manner.
- Bacterial activation hypothesis

During the anaerobic transformation of metronidazole in cecal content (examined in rats), the drug is converted into acetamide in yields of $8-15 \%$ and to $\mathrm{N}$-(2-hydroxyethyl)-oxamic acid in far lower quantities (6-9 - fold less). Acetamide is considered to be carcinogenic for rats, mice and, possibly, humans. A weak point of this hypothesis is that this mechanism can be prevented by parenteral administration of the drug, forgoing its passage through the gastrointestinal tract.

- Aerobic biotransformation hypothesis In humans, most of metronidazole is metabolized into two principal metabolites: 1-(2-hydroxyethyl)2-hydroxymethyl-5-nitroimidazole (HM) and 1acetic acid-2-methyl-5-nitroimidazole (AAM) to yields of approximately $40 \%$ and $15-20 \%$, respectively. Both have been found in patients' urine and plasma, but HM has been proved to influence cell lines with a functional P53 (the guardian of the genome, a tumor suppressor gene) - P53 protein levels increased in cell lines where HM was added. The induction of P53 is considered to be an early biomarker of DNA damage. According to published research, this hypothesis is the most reliable (13).

Research focused on P53 functionality in the genotoxicity of metronidazole and its metabolites described in the available literature were conducted on the cell lines of human cervical carcinoma (HeLa) and colon carcinoma (RKO and RKO-E6). The results obtained in the study showed increased cell proliferation in all cell lines treated with metronidazole, regardless of their P53 functionality, whereas HM induced increased proliferation only in cell lines with abnormal P53 (14). Oral squamous cell carcinoma is also included in a group of tumors whose development is connected with P53 dysfunction (15). Therefore, we can assume that metronidazole and its metabolites exert a similar effect on the cells of this type of cancer. The results of the present study showed a significant increase in cancer cell line viability under the influence of metronidazole. Heterogeneous outcomes were achieved depending on drug concentration and incubation time. The most profound effect was observed at the highest metronidazole concentrations $(100 \mu \mathrm{g} / \mathrm{mL}), 24 \mathrm{~h}$ after the addition of the drug. In order to check differences in DNA synthesis and confirm the results of the MTT assay, the $\left[{ }^{3} \mathrm{H}\right]$-thymidine incorporation test was performed. The same concentrations of metronidazole were used, and the results were collected after 24, 48 and $72 \mathrm{~h}$. The outcomes of the test did not show any statistically significant differences in DNA production 
depending on the concentration of the drug - the values fluctuated.

Early research was based on clinical trials involving patients treated with metronidazole for Crohn's disease, Trichomonas vaginalis, Helicobacter pylori or other infections. A great number of those epidemiological studies suggested a link between metronidazole and tumor occurrence, but the results were inconclusive. This ambiguity can be connected with the fact that it is impossible to prevent exposure to other carcinogenic factors in epidemiological trials. The issue has been extensively discussed in the case of patients with a Helicobacter pylori infection, which, per se, is a well-known gastric cancer risk factor and which is treated with metronidazole (16). A similar problem is observed in cervical cancer, where vaginal trichomoniasis is a risk factor and which is usually treated with metronidazole $(17,18)$. Results of the study on lymphocytes of patients after such treatment of Trichomonas vaginalis, showed a significant increase in the frequency of DNA single-strand breaks (ssb) prior to and following treatment (13). In a similar study, Menéndez and co-workers (19), examined the number of ssb and 'alkali labile'-sites in the DNA of patients treated with metronidazole. The results also demonstrated a substantial increase in DNA disruption in nine out of 10 individuals following treatment completion. The damage tended to be repaired after 14 days of drug discontinuation. Furthermore, plasma metronidazole concentrations correlated inversely with the intensity of DNA damage - the highest concentrations of the drug produced the least damage. Quite opposite results of similar assay were obtained by Fahrig and Engelke (20). They used lymphocytes of patients treated for different infections. Following the examination of cell nuclei prior to the first application, and $30 \mathrm{~min}$ to $2 \mathrm{~h}$ after the last one, they found no differences in DNA damage prior to and following treatment. Mitelman et al. (21) in their double-blind cross-over study involving patients treated for Crohn's disease also did not find any significant clastogenic effects of long-term metronidazole use on lymphocytes. The $\left[{ }^{3} \mathrm{H}\right]$-thymidine incorporation test in which we examined differences in DNA synthesis following the addition of various metronidazole concentrations also did not reveal any statistically significant changes.

Similar studies conducted on the different types of cancer cells also gave equivocal results. A decrease in cell viability, depending on drug concentration, was found in the DLD-1 colorectal cancer cell lines after metronidazole addition. Authors performed MTT test after 24, 48, or $72 \mathrm{~h}$ of incuba- tion with the drug at different concentrations $(0.1,1$, 10,50 , and $250 \mu \mathrm{g} / \mathrm{mL}$ ). Although, the conditions of the research was analogical to those in our research, the outcome was quite opposite - authors found the decrease in the viability of cells, depending on the concentration of the drug and time of incubation, with the highest value reaching $20 \%$. In the same study authors evaluated differences in DNA synthesis using the $\left[{ }^{3} \mathrm{H}\right]$-thymidine incorporation test, which demonstrated no statistically significant changes in comparison with control cells (22). The result of the analogical test in our study was similar. Different results were obtained in the research assessing the impact of metronidazole on the breast cancer. In the assay conducted in similar conditions as our study authors observed that metronidazole improved the survival of estrogen-independent (MDA-MB-231) or estrogen-dependent (MCF- 7) breast cancer cells, particularly when it was used in a high concentration $(250 \mu \mathrm{g} / \mathrm{mL})$. Mentioned results looked analogical to ours, but the outcome of the $\left[{ }^{3} \mathrm{H}\right]$-thymidine incorporation test was a bit different - authors found a significant increase in the MCF-7 cell line after $24 \mathrm{~h}$, at metronidazole concentration of $250 \mu \mathrm{g} / \mathrm{mL}$, comparing to control cells (23). Research evaluating the metronidazole influence on the breast cancer, conducted on the mice model showed similar results. Authors tried to estimate the risk of spontaneous mammary cancer development in mice after antibiotic treatment. They observed a significantly higher risk of tumor development in the metronidazole-treated group (approximately three times higher compared with the controls) and only a marginal increase in incidence in the case of gentamicin treatment (24).

The results of the aforementioned research are rather ambiguous. On the one hand, metronidazole is regarded as a proven carcinogen, on the other - as an anti-cancerous agent or even as a drug used in cancer treatment (alone or in combined therapy). Nonetheless, the International Agency for Research on Cancer (IARC) has qualified metronidazole as a substance possibly carcinogenic to humans (group 2B) (25).

There is a lack of similar studies in the available literature concerning head and neck cancer. It is important to evaluate if metronidazole can promote the development of this type of tumor since it is widely used in head and neck surgery as well as in the perioperative prevention of oral cancer surgeries. According to the results obtained in the present study, the MTT test proved that a high concentration of metronidazole stimulated oral cancer cell viability. On the other hand, the $\left[{ }^{3} \mathrm{H}\right]$-thymidine incorpora- 
tion test did not provide any statistically significant differences in cancer cell proliferation. Drug concentrations used in the research are close to its concentration in blood during treatment - in a regimen of $500 \mathrm{mg}$ dose four times a day, the minimum steady-state serum levels reached $21.3 \mu \mathrm{g} / \mathrm{mL}$ (26). Taking into consideration mentioned results, a potential risk of using metronidazole should be carefully analysed. Replacing metronidazole with a different antibiotic should possibly be considered in the treatment of patients with previously diagnosed oral cancer or premalignant lesions. This may limit local recurrence of the tumor or occurrence of second primary cancer, which are a frequent problem in the treatment of this disease.

\section{CONCLUSION}

The MTT test proved that metronidazole, at high concentrations, stimulates the viability of tongue squamous cell carcinoma cells. The $\left[{ }^{3} \mathrm{H}\right]-$ thymidine incorporation test did not provide any significant outcomes. Taking both assays into consideration, selecting metronidazole as an antibiotic should be performed very carefully, especially in the treatment patients with previously diagnosed oral cancer or premalignant lesions.

\section{Acknowledgments}

The study was conducted with the use of equipment purchased by the Medical University of Białystok as part of the OP DEP 2007-2013, Priority Axis I.3, contract No. POPW.01.03.00-20-008/09 and financially supported by the Medical University of Białystok, Poland (Project number: N/ST/MN/ 16/001/2227). The authors would like to thank $\mathrm{PhD}$ Jacek Marcinkiewicz for statistical consultation and MSc Justyna MacDonald for the professional language revision of the manuscript.

\section{Conflict of interest}

The authors declare no conflict of interest.

\section{REFERENCES}

1. Summary of investigation results metronidazole, Lansoprazole/Amoxicillin hydrate/Metronidazole, Rabeprazole sodium/Amoxicillin hydrate/ Metronidazole; PMDA (Pharmaceuticals and Medical Devices Agency), Aug 6 (2014).

2. Patil S., Mohiyuddin A., Kumar T.N.: Int. J. Pharm. Biomed. Res. 1, 65 (2010).
3. Roy U., Panwar A., Pandit A., Das K.S., Joshi B.: J. Clin. Diagn. Res. 10, OE01 (2016).

4. Raviraj J., Bokkasam V.K., Kumar V.S., Reddy U.S., Suman V.: Indian J. Dent. Res. 25, 83 (2014).

5. Barsukov Y.A., Gordeyev S.S., Tkachev S.I., Fedyanin M.Y., Perevoshikov A.G.: Colorectal Dis. 15, 1107 (2013).

6. Rosenblatt J.E., Edson R.S.: Mayo Clin. Proc. 62, 1013 (1987).

7. Skoropad V.Y., Berdov B.A., Zagrebin V.M.: Eur. J. Surg. Oncol. 29, 166 (2003).

8. King T., Agulnik M.: Published on Cancer Network (http://www.cancernetwork.com), September 15 (2010).

9. Ho M.W., Field E.A., Field J.K., Risk J.M., Rajlawat B.P. et al.: Br. J. Oral. Maxillofac. Surg. 51, 594 (2013).

10. Chaturvedi A.K., Anderson W.F., LortetTieulent J., Curado M.P., Ferlay J. et al.: J. Clin. Oncol. 31, 4550 (2013).

11. Napier S.S., Speight P.M.: J. Oral. Pathol. Med. 37, 1 (2008).

12. http://www.drugbank.ca/drugs/DB00916 (accessed on 15.04.2015).

13. Bendesky A., Menéndez D., Ostrosky-Wegman P.: Mutation Research. 511, 133 (2002).

14. Menendez D., Bendesky A., Rojas E.: Mutat. Res. 501, 57 (2002).

15. Abrahao A.C., Bonelli B.V., Nunes F.D., Dias E.P., Cabral M.G.: Braz. Oral. Res. 25, 34 (2011).

16. Pandey R., Misra V., Misra S.P., Dwivedi M., Kumar A., Tiwari B.K.: Asian Pac. J. Cancer Prev. 11, 583 (2010).

17. Beard C.M., Noller K.L., O'Fallon W.M., Kurland L.T., Dockerty M.B.: N. Eng. J. Med. 301, 519 (1979).

18. Management of cervical cancer, A national clinical guideline, SIGN - Scottish Intercollegiate Guidelines Network (2008).

19. Menéndez D., Rojas E., Herrera L.A., López M.C., Sordo M. et al.: Mutat. Res. 478, 153 (2001).

20. Fahring R., Engelke M.: Mutat. Res. 395, 219 (1997).

21. Mitelman F., Hartley-Asp B., Ursing B.: Lancet 2, 802 (1976).

22. Sadowska A., Kretowski R., Szynaka B., Cechowska-Pasko M., Car H.: Cancer Biother. Radiopharm. 28, 615 (2013).

23. Sadowska A., Prokopiuk S., Miltyk W., Surażyński A., Konończuk J. et al.: Adv. Med. Sci. 58, 90 (2013). 
24. Rossini A., Rumio C., Sfondrini L., Tagliabue E., Morelli D. et al.: Cancer Res. 66, 6219 (2006).

25. WHO, International Agency for Research on Cancer (IARC), Monographs on the evaluation of carcinogenic risks to humans, Suppl. 7, 250 (1987).

26. Ralph E.D., Clarke J.T., Libke R.D., Luthy R.P., Kirby W.M.M.: Antimicrob. Agents Chemother. 6, 691 (1974).

Received: 02.07. 2017 